TITLE:

\title{
Identification of quantitative trait loci associated with shoot sodium accumulation under low potassium conditions in rice plants
}

\section{$\operatorname{AUTHOR}(\mathrm{S}):$}

Miyamoto, Takuji; Ochiai, Kumiko; Takeshita, Saya; Matoh, Toru

\section{CITATION:}

Miyamoto, Takuji ...[et al]. Identification of quantitative trait loci associated with shoot sodium accumulation under low potassium conditions in rice plants. Soil Science and Plant Nutrition 2012, 58(6): 728-736

\section{ISSUE DATE:}

2012-12-13

URL:

http://hdl.handle.net/2433/188918

\section{RIGHT:}

(c) 2012 Japanese Society of Soil Science and Plant Nutrition; This is not the published version. Please cite only the published version.; この論文 は出版社版でありません。引用の際には出版社版をご確認ご利用くだ さい。 
Title:

\section{Identification of quantitative trait loci associated with shoot sodium accumulation under low potassium conditions in rice plants}

Authors:

Takuji Miyamoto, Kumiko Ochiai*, Saya Takeshita, and Toru Matoh

Institution:

Laboratory of Plant Nutrition, Division of Applied Life Sciences, Graduate School of Agriculture, Kyoto University, Kyoto, 606-8502 Japan

Running title:

$\mathrm{Na}$ accumulation in rice plants under low K supply

Corresponding author:

Kumiko Ochiai

Laboratory of Plant Nutrition, Division of Applied Life Sciences, Graduate School of Agriculture, Kyoto University, Kyoto, 606-8502 Japan

Tel/Fax: 075-753-6107

E-mail: pochi@kais.kyoto-u.ac.jp 


\begin{abstract}
Sodium application has marked beneficial effects on plant growth when the potassium supply is low. Under low K supply, three japonica rice (Oryza sativa L.) cultivars, Koshihikari, Nipponbare, and Sasanishiki, accumulated more sodium than three indica cultivars, IR36, IR64, and Kasalath, and the effect of sodium application on growth was greater in japonica Koshihikari plants than in indica IR64 plants. A quantitative trait locus analysis using a population of backcross inbred lines derived from japonica Koshihikari and indica Kasalath identified two significant loci associated with shoot sodium concentration on chromosomes 3 and 6 . The quantitative trait locus for shoot sodium accumulation on chromosome 6 was confirmed in a population of chromosome segment substitution lines. The major QTL detected in this study could be useful for increasing crop productivity under low $\mathrm{K}$ input.
\end{abstract}

Key words: Oryza sativa, potassium, QTL, sodium accumulation, substitution effect 


\section{INTRODUCTION}

Potassium $(\mathrm{K})$ is a basic component of crop fertilizers besides nitrogen and phosphorus, and the world demand for $\mathrm{K}$ fertilizer is increasing because of population growth and the expansion of intensive agriculture. The annual growth rate of the global demand for $\mathrm{K}$ fertilizer was estimated as 3.0\% for the period 2007-2011 (FAO 2008) and 3.8\% for the period 2011-2014 (Heffer and Prud'homme 2010). Although there is no urgent concern regarding reduced world K reserves, the cost of $\mathrm{K}$ fertilizer is increasing because the reserves are concentrated in a few countries (USDA 2011, USGS 2012). Furthermore, excessive application of fertilizers causes environmental pollution. Therefore, it is important to decrease $\mathrm{K}$ fertilizer use for both economic and ecological reasons; to minimize $\mathrm{K}$ fertilizer use without decreasing crop yields it is important to improve the efficiency with which crops use $\mathrm{K}$.

Sodium (Na) is not an essential element for higher plants; however, application of Na salts is beneficial when plants are grown under low K conditions (Lehr 1953, Flowers and Läuchli 1983, Wakeel et al. 2011). The extent of the beneficial effect of Na salts differs from species to species (Lehr 1953). Takahashi and Maejima (1998) demonstrated that Na application did not counteract the growth reduction in K-deficient maize (Zea mays L.) and kidney bean (Phaseolus vulgaris L.) plants, but the growth of K-deficient barley (Hordeum vulgare L.) plants recovered to up to $78 \%$ of that of K-sufficient plants. Cultivar differences with respect to the effect of $\mathrm{Na}$ application under low K supply was also found for tomato (Solanum lycopersicum L.; Figdore et al. 1987). The extent of growth stimulation by Na salts in different species and cultivars was correlated positively with Na concentration in the shoots (Takahashi and Maejima 1998, Figdore et al. 1987); therefore, it is likely that the ability to accumulate $\mathrm{Na}$ is important for the utilization of $\mathrm{Na}$ under low $\mathrm{K}$ conditions. As $\mathrm{Na}$ is ubiquitous and its concentration in the soil solution is 
generally higher than that of K (Flowers and Läuchli 1983), enhancement of the ability of crops to take up soil Na will enhance crop productivity.

Rice (Oryza sativa L.), one of the most important crops in humid Asia, consumes $13 \%$ of world K fertilizer supplies (Heffer 2009), and the grain yield of rice decreased by $10 \%$ when $\mathrm{K}$ fertilizer was not applied in a long-term field experiment (Momii and Izawa 2007). Studies on the substitution of $\mathrm{K}$ by $\mathrm{Na}$ in rice plants showed that rice plants took up more $\mathrm{Na}$ under low $\mathrm{K}$ conditions than under adequate K conditions (Hasegawa et al. 1987, Takahashi and Maejima 1998, Akai et al. 2012), and supplying $\mathrm{NaCl}$ made the flaccid rice leaf erect and increased plant dry weight under K-deficient conditions (Yoshida and Castaneda 1969). Takahashi and Maejima (1998) estimated that supplementation with $\mathrm{NaCl}$ could reduce the growth reduction caused by $\mathrm{K}$ deficiency to $52 \%$. Horie et al. (2007) indicated that the Na transporter OsHKT2;1 contributed to Na uptake under K-deficient conditions.

The final goal of our study is to breed new rice that can take up more soil $\mathrm{Na}$ and produce a high yield without $\mathrm{K}$ fertilizer application. In this report, we first reveal cultivar differences in shoot $\mathrm{Na}$ accumulation in rice under low $\mathrm{K}$ conditions and investigate the relation between $\mathrm{Na}$ accumulation ability and growth response under low $\mathrm{K}$ conditions. We then performed a quantitative trait locus (QTL) analysis to identify the chromosomal regions responsible for the difference in shoot $\mathrm{Na}$ accumulation, which could provide a foundation for breeding rice with high $\mathrm{Na}$ accumulation ability and therefore high yield under low $\mathrm{K}$ fertilizer input.

\section{MATERIALS AND METHODS}

\section{Plant materials}

Three japonica cultivars of rice (Oryza sativa L.), Koshihikari, Nipponbare, and Sasanishiki, and 
three indica cultivars, IR36, IR64, and Kasalath, were used in this study.

Two hybrid populations, a backcross inbred line (BIL) population (Ma et al. 2002) and a chromosome segment substitution line (CSSL) (Ebitani et al. 2005), both derived from a cross between the japonica Koshihikari and the indica Kasalath, were obtained from the Rice Genome Resource Center (RGRC), Tsukuba, Japan. The BIL population consisted of 182 lines, of which 132 randomly selected lines were used in this study. The CSSLs consisted of 39 lines carrying Kasalath chromosome segments on a genetic background of Koshihikari. The substituted chromosome segments covered most of the 12 chromosomes by 39 lines.

The genotype data of BILs and CSSLs were downloaded from the RGRC website (http://www.rgrc.dna.affrc.go.jp/). The physical position of the marker probes was based on the Os-Nipponbare-Reference-IRGSP-1.0 in the rice annotation project database (Rice Annotation Project 2008).

\section{Culture conditions}

Seeds were soaked for 3 days at $30^{\circ} \mathrm{C}$ in distilled water supplemented with a fungicide $(3 \% \mathrm{w} / \mathrm{v}$, TORIFUMIN; Nippon Soda Co., Ltd., Tokyo, Japan). Ten seeds were sown on a nylon mesh (18 mesh, $24 \times 36 \mathrm{~mm}$ ) stretched on a plastic frame then floated on a culture solution. The plants on the mesh were raised in a growth chamber (NS-280 FHW, Takayama Seisakusyo, Kyoto, Japan) under the following conditions: temperature $30^{\circ} \mathrm{C}$, relative humidity $80 \%$, photoperiod $12 \mathrm{~h}$, and light intensity $350 \mu \mathrm{mol} \mathrm{m}^{-2} \mathrm{~s}^{-1}$.

The culture solution was prepared in distilled water. The control culture solution contained $0.75 \mathrm{~mol} \mathrm{~m}^{-3}\left(\mathrm{NH}_{4}\right)_{2} \mathrm{SO}_{4}, 0.25 \mathrm{~mol} \mathrm{~m}^{-3}\left(\mathrm{NH}_{4}\right)_{2} \mathrm{HPO}_{4}, 0.75 \mathrm{~mol} \mathrm{~m}^{-3} \mathrm{KCl}, 0.50 \mathrm{~mol} \mathrm{~m}^{-3} \mathrm{CaCl}_{2}$, and $0.50 \mathrm{~mol} \mathrm{~m}^{-3} \mathrm{MgCl}_{2}$. Iron was supplied at $5.0 \mathrm{~g} \mathrm{Fe} \mathrm{m}^{-3}$ as Fe-citrate for the comparison 
among rice cultivars and the growth experiment, or FeNa-EDTA for the experiment using BIL and CSSL populations. When FeNa-EDTA was used, the culture solution basically contained $\mathrm{Na}$ at $0.09 \mathrm{~mol} \mathrm{~m}^{-3}$. Micronutrients were supplied according to Arnon's formula (Hewitt 1966). The $\mathrm{pH}$ was adjusted to 6.0 with $\mathrm{HCl}$. For the low $\mathrm{K}$ treatment, the $\mathrm{KCl}$ concentration was decreased. Supplemental $\mathrm{Na}$ was added as $\mathrm{NaCl}$.

\section{Comparison of shoot $\mathrm{Na}$ and $\mathrm{K}$ concentrations among rice cultivars}

To evaluate the cultivar difference in shoot $\mathrm{Na}$ and $\mathrm{K}$ concentration, six cultivars were grown in $2 \mathrm{~L}$ of culture solution containing 0.08 or $0.75 \mathrm{~mol} \mathrm{~m}^{-3} \mathrm{KCl}$. NaCl concentration in the culture solution was $0.38 \mathrm{~mol} \mathrm{~m}^{-3}$. Plants were harvested 10 days after sowing. Plants on a mesh were divided into three groups and subjected to analysis.

\section{Growth experiment}

Seedlings of Koshihikari and IR64 were grown on the control culture solution as described above. Seven days after sowing, plants with uniform size were selected and two plants each were transferred to a 40-mL glass vial to start the low $\mathrm{K}$ treatment. The plants were fixed in the vial with a piece of sponge. The $\mathrm{KCl}$ concentration in culture solution was $0.08 \mathrm{~mol} \mathrm{~m}^{-3}$ and the $\mathrm{NaCl}$ concentration was 0 or $0.38 \mathrm{~mol} \mathrm{~m}^{-3}$. At 3, 7, 10, and 14 days after the beginning of the low $\mathrm{K}$ treatment, the roots were gently blotted and the fresh weights of the plants were determined. After fresh weight determination, plants were returned to the freshly prepared culture solution. Plants were harvested 18 days after the beginning of the low $\mathrm{K}$ treatment, and shoot dry weights and shoot $\mathrm{Na}$ and $\mathrm{K}$ concentrations were determined. The experiment was performed with three replications. 


\section{Low K treatments for BIL and CSSL populations}

For QTL analysis using the $\mathrm{BIL}$ population, $\mathrm{KCl}$ and $\mathrm{NaCl}$ concentrations in the culture solution were 0.08 and $0.38 \mathrm{~mol} \mathrm{~m}^{-3}$, respectively. Thirty-three lines of BILs with the parent cultivars Koshihikari and Kasalath were grown in a 10-L plastic container and harvested 9 days after sowing. All plants on a mesh were bulked and subjected to analysis.

CSSLs were grown in culture solution containing $\mathrm{KCl}$ and $\mathrm{NaCl}$, both at $0.38 \mathrm{~mol} \mathrm{~m}^{-3}$. Each of the six lines and Koshihikari and Kasalath were grown in a 2-L plastic container and harvested 10 days after sowing. The plants on a mesh were divided into three groups and subjected to analysis.

\section{Na and K determination}

At harvest, the plants were separated into shoots and roots, and the shoots were rinsed with distilled water and blotted dry. The shoots were dried in an oven at $70^{\circ} \mathrm{C}$ for 2 days and weighed. The shoots in a test tube were digested with $\mathrm{HNO}_{3}-\mathrm{H}_{2} \mathrm{SO}_{4}$ and the digest solution was brought to $20 \mathrm{~mL}$ with $100 \mathrm{~mol} \mathrm{~m}^{-3} \mathrm{HCl}$. Concentrations of $\mathrm{Na}$ and $\mathrm{K}$ were determined by flame photometry (AA-6200, Shimazu Seisakusyo, Kyoto, Japan).

\section{QTL analysis}

QTL analyses were performed using QGene software (Nelson 1997). The simple interval mapping method was used and the log likelihood (LOD) score was used to estimate the QTL for traits. Based on permutation tests with 1000 permutations, a threshold of $2.9(P<0.05)$ was applied to QTL detection. 


\section{RESULTS}

\section{Cultivar differences in shoot $\mathrm{Na}$ concentration under low $\mathrm{K}$ condition}

Shoot $\mathrm{K}$ and $\mathrm{Na}$ concentrations of the six rice cultivars are shown in Fig. 1. For both $\mathrm{K}$ and $\mathrm{Na}$ concentration, two-way ANOVA revealed significant differences between treatments and among cultivars, and their interaction was also significant $(P<0.01)$. The shoot $\mathrm{K}$ concentration was decreased at the lower $\mathrm{K}$ concentration in the medium (Fig. 1). The Na concentration in the culture solution was uniform under both treatments, but there was a significant difference between treatments in shoot $\mathrm{Na}$ concentration (Fig. 1). The shoot $\mathrm{Na}$ concentration was low in the control $\left(0.75 \mathrm{~mol} \mathrm{~K} \mathrm{~m}^{-3}\right)$ condition, but increased at the low medium $\mathrm{K}$ concentration. The shoot $\mathrm{Na}$ concentration under the low $\mathrm{K}$ condition was higher in the japonica cultivars (Koshihikari, Nipponbare, and Sasanishiki) compared with the indica cultivars (IR36, IR64, and Kasalath).

\section{Contribution of Na accumulation ability to growth}

To clarify the significance of $\mathrm{Na}$ accumulating ability for better growth under the low $\mathrm{K}$ condition, the effect of $\mathrm{Na}$ application on the growth rate of Koshihikari, a cultivar that accumulates high levels of $\mathrm{Na}$, and IR64, a cultivar that accumulates low $\mathrm{Na}$ levels, was compared. Growth rate was similar in both cultivars when $\mathrm{NaCl}$ was not applied (Fig. 2); however, $\mathrm{NaCl}$ application significantly increased the fresh weight of Koshihikari plants $(P<$ 0.05). The fresh weight of IR64 plants was slightly increased by $\mathrm{NaCl}$ application, but the difference between the treatments was not significant. Also, shoot dry weights of 25-day-old plants were not different between cultivars when $\mathrm{NaCl}$ was not applied, but significantly higher 
in Koshihikari plants than IR64 plants under $\mathrm{NaCl}$ application (Table 1). The shoot $\mathrm{NaCl}$ concentration of Koshihikari plants was significantly higher than that of IR64 plants (Table 1).

\section{QTL for shoot Na concentration}

A total of 132 BILs and their parent cultivars, Koshihikari and Kasalath, were grown using four containers, each with 10-L capacity. The parent cultivars were included in each container as the reference. The mean shoot $\mathrm{K}$ concentration was $292 \pm 37.8 \mu \mathrm{mol} \mathrm{g}{ }^{-1} \mathrm{DW}$ for Koshihikari and $324 \pm 56.4 \mu \mathrm{mol} \mathrm{g}^{-1} \mathrm{DW}$ for Kasalath. The mean shoot Na concentration was $333 \pm 77.5 \mu \mathrm{mol}$ $\mathrm{g}^{-1} \mathrm{DW}$ for Koshihikari and $85.5 \pm 19.7 \mu \mathrm{mol} \mathrm{g}{ }^{-1} \mathrm{DW}$ for Kasalath. The values varied among containers, however; the ratio of the values of Kasalath to Koshihikari were similar in all the containers: $1.04,1.20,1.06$, and 1.14 for $\mathrm{K}$, and $0.27,0.25,0.25$, and 0.25 for Na. To normalize the differences among containers, the BIL/Koshihikari concentration ratios in the same container were used for analysis.

The relative shoot $\mathrm{K}$ concentrations of BILs ranged from 0.61 to 1.41 . The distribution of relative shoot $\mathrm{Na}$ concentrations was broader than that of $\mathrm{K}$, and ranged from 0.24 to 1.67 (Fig. 3).

QTL analysis was performed using 161 markers. A QTL peak was detected for shoot K concentration close to marker C25 on chromosome 3 (LOD = 4.0, Table 2, Fig. 4). At the C25 locus, the Koshihikari allele increased shoot K concentration, and genotype explained $12 \%$ of the phenotypic variation. For the shoot Na concentration, two QTL peaks were detected. One was close to marker C721 on chromosome $3(\mathrm{LOD}=3.0)$, and the other was close to marker R1167 on chromosome 6 (LOD = 17.1, Table 2, Fig. 4). The Kasalath allele increased shoot Na concentration at the C721 locus, and the Koshihikari allele increased shoot $\mathrm{Na}$ concentration at 
the R1167 locus. Genotype at the C721 and R1167 loci explained 8\% and 74\% of the phenotypic variation, respectively.

\section{Sodium accumulation in CSSLs}

Figure 5 indicates the relative shoot Na concentrations of CSSLs. Shoot Na concentration was similar to that of the corresponding genetic background, Koshihikari, in most of the CSSLs; however, shoot Na concentrations of SL215 and SL218 were low, and the lower Na concentrations were reproduced in several independent experiments. Both SL215 and SL218 carry the Kasalath-derived allele on chromosome 6; moreover, the shoot Na concentrations of SL216 and SL217, which also carry the Kasalath derived allele on chromosome 6, were similar to that of Koshihikari (Fig. 5). It was therefore considered that the gene responsible for $\mathrm{Na}$ accumulation was in the Kasalath-derived chromosome region common to SL215 and SL218, but excluding the Kasalath-derived region in SL216 and SL217. The candidate region was delimited between marker R2549 and the end of the long arm (Fig. 6), and corresponded to the QTL detected in the BIL population. The physical length of the candidate region was approximately $6.4 \mathrm{Mb}$.

Some lines, such as SL208, SL209, SL210, SL212, SL238, and SL239, showed higher shoot $\mathrm{Na}$ concentrations compared with Koshihikari, but the data were not reproducible in parallel experiments (data not shown).

\section{DISCUSSION}

Efficient $\mathrm{K}$ use by crops is an integral phenomenon of $\mathrm{K}$ uptake ability by the root and internal $\mathrm{K}$ use efficiency. Internal $\mathrm{K}$ use efficiency is determined by several factors, such as translocation 
capacity, ability to maintain cytosolic K, and ability to substitute K by Na (Rengel and Damon 2008). Cultivar or ecotypical differences in K use efficiency have been shown in several plant species, such as barley (Pettersson and Jensen 1983), wheat (Triticum aestivum L.) (Woodend and Glass 1993), Brassica oleracea L. (White et al. 2010), tomato (Figdore et al. 1987), rice (Yang et al. 2003), and Arabidopsis thaliana (Harada and Leigh 2006), using dry weight under low-K stress, $\mathrm{K}$ concentration in plants, or dry weight production per unit of $\mathrm{K}$ as the index. In this study, we examined the $\mathrm{Na}$ accumulation ability of rice plants under low $\mathrm{K}$ supply as an index of $\mathrm{K}$ use efficiency. Shoot $\mathrm{Na}$ concentrations in rice plants were low under the control condition, but were higher at the low K concentration in the culture solution (Fig. 1), consistent with previous findings (Hasegawa et al. 1987, Takahashi and Maejima 1998). Three japonica cultivars, however, accumulated more Na compared with three indica cultivars (Fig. 1). Though the rice cultivars used in this experiment also differed in their shoot $\mathrm{K}$ concentrations under low K supply, the variation was much smaller than that in the shoot Na concentrations (Fig. 1). Such variation among cultivars in $\mathrm{Na}$ accumulation has not been described previously, and this result suggests that the $\mathrm{Na}$ accumulation ability of indica cultivars could be enhanced through crossing with japonica cultivars.

Rice cultivars with different Na-accumulating ability showed different growth responses to $\mathrm{Na}$ application under the low K supply. The growth rate of Koshihikari, a high Na-accumulating cultivar, was significantly increased by the $\mathrm{NaCl}$ application, whereas the effect of $\mathrm{NaCl}$ application on IR64, a low Na-accumulating cultivar, was negligible (Fig. 2, Table 1). This result indicates the contribution of $\mathrm{Na}$ accumulation ability to improved growth of rice under low $\mathrm{K}$ conditions and the possibility that the enhancement of Na-accumulating ability results in a better yield under low $\mathrm{K}$ input farming. 
The QTL analysis revealed two significant loci responsible for the cultivar difference in shoot Na concentration (Table 2), and a significant QTL for shoot K concentration was also detected despite similar shoot $\mathrm{K}$ concentrations in the parent cultivars (Table 2). Wu et al. (1998) performed QTL analyses for growth parameters and $\mathrm{K}$ uptake of rice under low $\mathrm{K}$ stress and found several QTLs on chromosomes 2, 3, 4, 5, 7, and 8, but none of these correspond to the QTLs detected in this study. This might be because of the difference in the combination of parent cultivars or the different culture conditions.

One of the QTLs for Na uptake was detected near marker C721 on chromosome 3, and the Kasalath allele increased shoot $\mathrm{Na}$ concentration at this QTL. Although the shoot $\mathrm{Na}$ concentration of a CSSL line SL208, which may carry the Kasalath-derived QTL allele, was higher than that of Koshihikari in the confirmation experiment (Fig. 5), the higher shoot $\mathrm{Na}$ concentration was not detected in a similar trial. More intensive examination is necessary in order to validate the QTL.

The other QTL for Na uptake, which was located at the end of chromosome 6, strongly contributed to the phenotypic variation (Table 2, Fig. 4), and this QTL was confirmed in the CSSLs (Fig. 5). In previous studies, several QTLs for Na uptake in rice under $\mathrm{NaCl}$ salinity were detected (Koyama et al. 2001, Lin et al. 2004), one of which was located at the end of chromosome 6 (Koyama et al. 2001). However, it is uncertain whether these two QTL genes are identical, because the Na uptake of SL215 and SL218, which are CSSLs with the Kasalath-derived allele at the end of chromosome 6, under $100 \mathrm{~mol} \mathrm{~m}^{-3} \mathrm{NaCl}$ salinity was not different from that of Koshihikari in a preliminary experiment (data not shown).

A database search showed the occurrence of a transporter gene, OsHKT2;1, in the $6.4 \mathrm{Mb}$ candidate region on chromosome 6 . OsHKT2;1 is a Na transporter, which has been characterized 
in the context of salt injury in rice (Horie et al. 2001, Golldack et al. 2002). Horie et al. (2007) later showed that OsHKT2;1 was responsible for Na uptake under K-deficient conditions, on the basis of the result that Tos17 insertion mutants, in which the OsHKT2;1 gene is disrupted, accumulated less $\mathrm{Na}$. They also showed that OsHKT2;1 expression was induced in the K-deficient condition. Because of its position on the chromosome and its function, it is likely that $O s H K T 2 ; 1$ is responsible for the cultivar difference in Na accumulation under low $\mathrm{K}$ conditions. However, we observed that the predicted amino acid sequences of OsHKT2;1 were identical in Koshihikari and IR64 (data not shown). Furthermore, Oomen et al. (2012) reported that the main functional properties of OsHKT2;1 were conserved in the six kinds of protein variants that were identified in a survey of 49 diverse rice cultivars. Therefore, it might be the level of expression rather than the functional difference that correlates with the cultivar difference in $\mathrm{Na}$ accumulation found in this study. We are examining the expression level of OsHKT2;1 to verify this possibility. In addition, we are trying to narrow the candidate region using the map-based cloning technique, because many other genes are annotated in the candidate region.

The results reported here indicate that the $\mathrm{Na}$ uptake of indica cultivars under low $\mathrm{K}$ input conditions could be increased, resulting in better performance under low $\mathrm{K}$ input. Marker-assisted breeding of near-isogenic lines of the popular indica cultivar IR64, in which the QTL region on chromosome 6 is substituted by the allele from Koshihikari, is now in progress. To enhance the Na uptake ability of japonica rice further, it is necessary to screen more diverse cultivars and determine high-Na uptake cultivars as a gene source.

\section{ACKNOWLEDGMENTS}


This work was supported by a grant from the Ministry of Agriculture, Forestry, and Fisheries of

Japan (Molecular cloning and characterization of agronomically important genes of rice IPG0007). 


\section{REFERENCES}

Akai N, Washio T, Tabuchi M, Ishibashi E 2012: Investigation of chemical properties of rice paddy soil in southern Okayama and preparation of guidelines for optimizing potassium fertilizer application based on the sodium content in rice shoots. Jpn. J. Soil Sci. Plant Nutr., 83, 266-273. (in Japanese with English summary)

Ebitani T, Takeuchi Y, Nonoue Y, Yamamoto T, Takeuchi K, Yano M 2005: Construction and evaluation of chromosome segment substitution lines carrying overlapping chromosome segments of indica rice cultivar 'Kasalath' in a genetic background of japonica elite cultivar 'Koshihikari'. Breed. Sci., 55, 65-73.

FAO 2008: Current world fertilizer trends and outlook to 2011/12. FAO, Rome, Italy.

Figdore SS, Gabelman WH, Gerloff GC 1987: The accumulation and distribution fo sodium in tomato strains differing in potassium efficiency when grown under low-K stress. Plant Soil, 99, 85-92.

Flowers TJ, Läuchli A 1983: Sodium versus potassium: Substitution and compartmentation. In Encyclopedia of Plant Physiology New Series Volume 15B Inorganic Plant Nutrition, Ed. Läuchli A, Bieleski RL, pp 651-681. Springer-Verlag, Berlin, Germany.

Golldack D, Su H, Quigley F, Kamasani UR, Munoz-Garay C, Balderas E, Popova OV, Bennett J, Bohnert HJ, Pantoja O 2002: Characterization of a HKT-type transporter in rice as a general alkali cation transporter. Plant J., 31, 529-542.

Harada H, Leigh R 2006: Genetic mapping of natural variation in potassium concentrations in shoots of Arabidopsis thaliana. J. Exp. Bot., 57, 953-960. 
Hasegawa W, Saitoh K, Yasui T, Hisamasue T, Shiojima M 1987: Potassium and sodium uptake by rice plant. Bull. Miyagi Prefect. Agric. Res. Cent., 55, 19-36. (in Japanese with English summary)

Heffer P 2009: Assessment of fertilizer use by crop at the global level. 2006/07-2007/08. http://www.fertilizer.org (March, 2012)

Heffer P, Prud'homme M 2010: Fertilizer outlook 2010-2014. http://www.fertilizer.org (March, 2012)

Hewitt EJ 1966: The composition of the nutrient solution In Sand and Water Culture Methods Used in the Study of Plant Nutrition. Ed, Hewitt E, pp 190. Farnham Royal Bucks, Commonwealth Agricultural Bureaux, Slough, UK.

Horie T, Costa A, Kim TH, Han MJ, Horie R, Leung H-Y, Miyao A, Hirochika H, An G, Schroeder JI 2007: Rice OsHKT2;1 transporter mediates large $\mathrm{Na}^{+}$influx component into $\mathrm{K}^{+}$-starved roots for growth. EMBO J., 26, 3003-3014.

Horie T, Yoshida K, Nakayama H, Yamada K, Oiki S, Shinmyo A 2001: Two types of HKT transporters with different properties of $\mathrm{Na}^{+}$and $\mathrm{K}^{+}$transport in Oryza sativa. Plant J., 27, 129-138.

Koyama ML, Levesley A, Koebner RMD, Flowers TJ, Yeo AR 2001: Quantitative trait loci for component physiological traits determining salt tolerance in rice. Plant Physiol., 125, 406-422.

Lehr JJ 1953: Sodium as a plant nutrient. J. Sci. Food. Agric., 4, 460-471.

Lin HX, Zhu MZ, Yano M, Gao JP, Liang ZW, Su WA, Hu XH, Ren ZH, Chao DY 2004: QTLs for $\mathrm{Na}^{+}$and $\mathrm{K}^{+}$uptake of the shoots and roots controlling rice salt tolerance. Theor. Appl. Genet., 108, 253-260. 
Ma JF, Shen RF, Zhao ZQ, Wissuwa M, Takeuchi Y, Ebitani T, Yano M 2002: Response of rice to Al stress and identification of quantitative trait loci for Al tolerance. Plant Cell Physiol., 43, 652-659.

Momii T, Izawa T 2007: The yielding of rice and the effects of each element in consecutive 77-year lacking of four elements and fertilizing with compost. Jpn. J. Crop. Sci., 76, 288-294. (in Japanese with English summary)

Nelson JC 1997: QGENE: Software for marker-based genomic analysis and breeding. Molecul. Breed., 3, 239-245.

Oomen JFJR, Benito B, Sentenac H, Rodríguez-Navarro A, Talón M, Véry AA, Domingo C 2012: HKT2;2/1, a K ${ }^{+}$-permeable transporter identified in a salt-tolerant rice cultivar through surveys of natural genetic polymorphism. Plant J., doi:

10.111/j.1365-313X.2012.05031.X

Pettersson S, Jensen P 1983: Variation among species and varieties in uptake and utilization of potassium. Plant Soil, 72, 231-237.

Rengel Z, Damon PM 2008: Crops and genotypes differ in efficiency of potassium uptake and use. Physiol. Plant., 133, 624-636.

Rice Annotation Project 2008: The rice annotation project database (RAP-DB): 2008 update. Nucleic Acid Res., 36, D1028-33.

Takahashi E, Maejima K 1998: Comparative research on sodium as a beneficial element for crop plants. Mem. Fac. Agric. Kinki Univ., 31, 57-72. (in Japanese with English summary)

USDA 2011: Fertilizer use and price. http://www.ers.usda.gov/Data/FertilizerUse/ (March, 2012) 
USGS 2012: Mineral Commodity summaries 2012.

http://minerals.usgs.gov/minerals/pubs/mcs/2012/mcs2012.pdf (March, 2012)

Wakeel A, Farooq M, Qadir M, Schubert S 2011: Potassium substitution by sodium in plants. Crit. Rev. Plant Sci., 30, 401-413.

White PJ, Hammond JP, King GJ, Bowen HC, Hayden RM, Meacham MC, Spracklen WP, Broadley MR 2010: Genetic analysis of potassium use efficiency in Brassica oleracea. Ann. Bot., 105, 1199-1210.

Woodend JJ, Glass ADM 1993: Genotype-environment interaction and correlation between vegetative and grain production measures of potassium use-efficiency in wheat (Triticum aestivum L) grown under potassium stress. Plant Soil, 151, 39-44.

Wu P, Ni JJ, Luo AC 1998: QTLs underlying rice tolerance to low-potassium stress in rice seedlings. Crop Sci., 38, 1458-1462.

Yang XE, Liu JX, Wang WM, Li H, Luo AC, Ye ZQ, Yang Y 2003: Genotypic differences and some associated plant traits in potassium internal use efficiency of lowland rice (Oryza sativa L.). Nutr. Cycl. Agroecosyst., 67, 273-282.

Yoshida S, Castaneda L 1969: Partial replacement of potassium by sodium in the rice plant under weakly saline conditions. Soil Sci. Plant Nutr., 15, 183-186. 
Table 1 Shoot dry weight, shoot $\mathrm{K}$ concentration, and shoot $\mathrm{Na}$ concentration of 25-day-old rice plants grown under low $\mathrm{K}$ condition. Plants were grown and exposed to low $\mathrm{K}$ as indicated in the legend to Fig. 2, and harvested 18 days after the beginning of low $\mathrm{K}$ treatment.

\begin{tabular}{lccc}
\hline & $\begin{array}{c}\text { Shoot dry weight } \\
(\mathrm{mg})\end{array}$ & $\begin{array}{c}\text { Shoot K conc. } \\
\left(\mu \mathrm{mol} \mathrm{g}^{-1} \mathrm{dw}\right)\end{array}$ & $\begin{array}{c}\text { Shoot Na conc. } \\
\left(\mu \mathrm{mol} \mathrm{g} \mathrm{dw}^{-1}\right)\end{array}$ \\
\hline$-\mathrm{NaCl}$ & & & \\
Koshihikari & $122^{\mathrm{b}} \pm 10.3$ & $175^{\mathrm{a}} \pm 10.5$ & $1.13^{\mathrm{c}} \pm 0.74$ \\
IR64 & $114^{\mathrm{b}} \pm 10.5$ & $165^{\mathrm{a}} \pm 7.18$ & $0.91^{\mathrm{c}} \pm 0.26$ \\
$+\mathrm{NaCl}$ & & & \\
Koshihikari & $159^{\mathrm{a}} \pm 0.81$ & $133^{\mathrm{b}} \pm 4.62$ & $170^{\mathrm{a}} \pm 18.7$ \\
\multicolumn{1}{l}{ IR64 } & $123^{\mathrm{b}} \pm 3.00$ & $148^{\mathrm{b}} \pm 5.90$ & $87.8^{\mathrm{b}} \pm 12.6$ \\
\hline
\end{tabular}

Values are means and SD (n=3). Values in a column followed by the same letter are not significantly different $(P<0.05$, Holm-adjusted $\mathrm{t}$-test $)$. 
Table 2 QTLs for shoot $\mathrm{K}$ and shoot $\mathrm{Na}$ concentrations in rice under low $\mathrm{K}$ condition.

\begin{tabular}{lccccc}
\hline Traits & Chr. & Nearest marker & LOD & Additive effect ${ }^{\dagger}$ & Contribution (\%) $^{\circ}$ \\
\hline Shoot K conc. & 3 & C25 & 4.0 & 0.056 & 12 \\
Shoot Na conc. & 3 & C721 & 3.0 & -0.13 & 8 \\
& 6 & R1167 & 17.1 & 0.26 & 74 \\
\hline
\end{tabular}

$\dagger$ Positive values indicate the allele from Koshihikari increases the phenotypic value.

*Values indicate the phenotypic variance explained by each QTL 
(a)

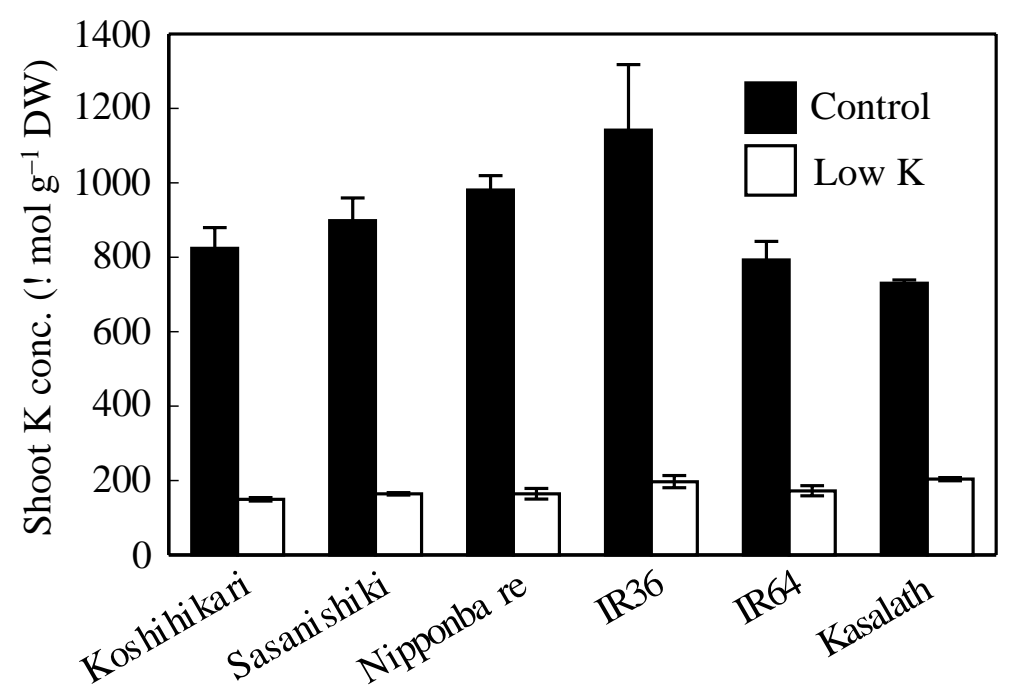

(b)

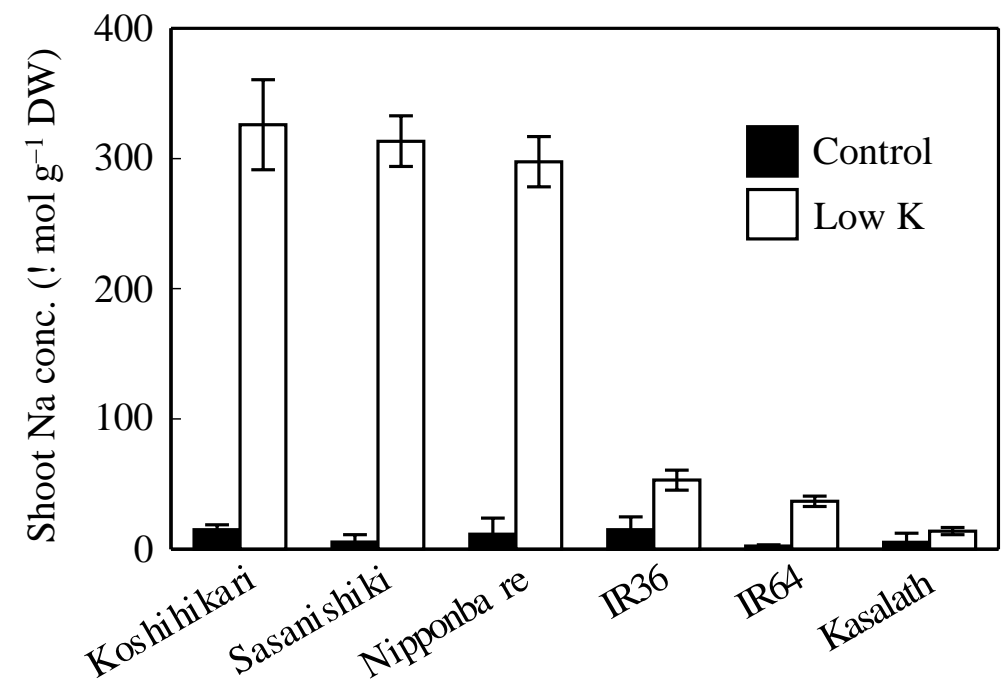

Figure 1 Shoot $\mathrm{K}$ and Na concentrations in 10-day-old seedlings of six rice cultivars. (a) Shoot K concentration, (b) shoot $\mathrm{Na}$ concentration. Plants were grown in a culture solution containing $\mathrm{KCl}$ at $0.75 \mathrm{~mol} \mathrm{~m}^{-3}$ (Control) or $0.08 \mathrm{~mol} \mathrm{~m}^{-3}$ (Low K). The culture solution was supplemented with $0.38 \mathrm{~mol} \mathrm{~m}{ }^{-3} \mathrm{NaCl}$ for both $\mathrm{K}$ treatment conditions. Values are means with $\mathrm{SD}(\mathrm{n}=3)$. For both the $\mathrm{K}$ and the $\mathrm{Na}$ data, there were significant differences between the $\mathrm{K}$ treatment and among cultivars, and the interaction was also significant in two-way ANOVA $(P<0.01)$. 
(a)

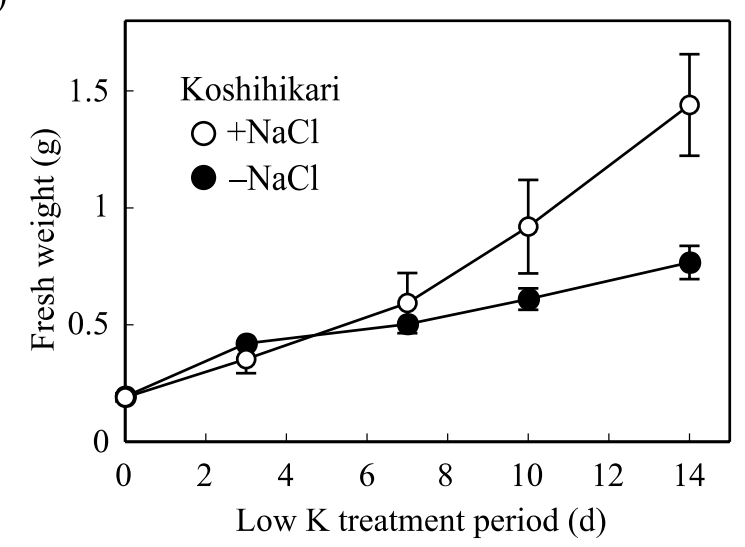

(b)

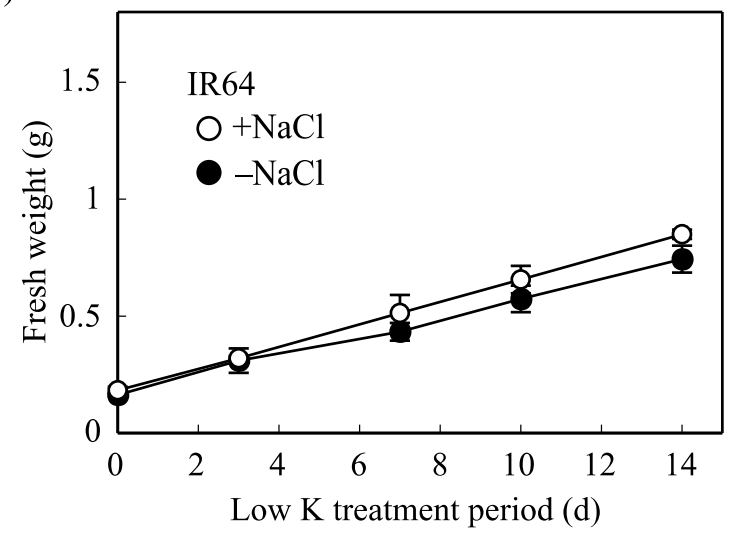

Figure 2 Changes in fresh weight of rice plants under the low K condition. (a) Koshihikari, (b) IR64. Seven-day-old seedlings raised in a K-sufficient condition were transferred to low K culture solution. The $\mathrm{K}$ concentration in the culture solution for the low $\mathrm{K}$ treatment was 0.08 mol $\mathrm{m}^{-3}$ and the $\mathrm{NaCl}$ concentrations were 0 (black circle) or 0.38 (white circle) $\mathrm{mol} \mathrm{m}^{-3}$. Values are means with $\mathrm{SD}(\mathrm{n}=3)$. Significance of the factors are as follows. Koshihikari: $\mathrm{NaCl}^{*}$, period $^{* *}, \mathrm{NaCl} \times$ period $^{* *}, \mathrm{IR64}: \mathrm{NaCl}^{\mathrm{ns}}$, period ${ }^{* *}, \mathrm{NaCl} \times$ period $^{\mathrm{ns}}(\mathrm{ns}$, not significant; $* P<$ $0.05 ; * * P<0.01$, two-way repeated measures ANOVA). 
(a)

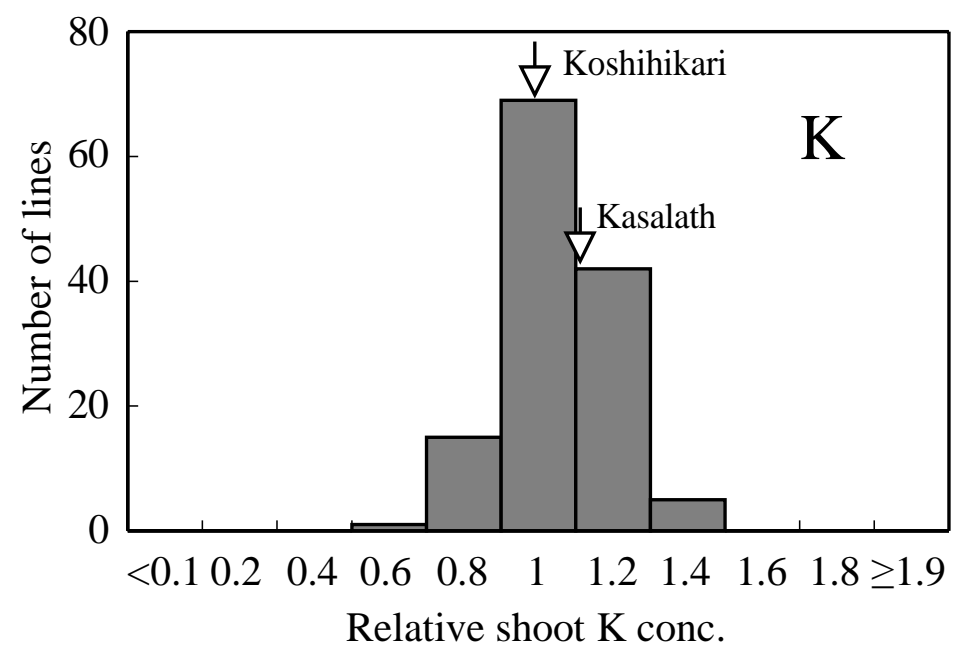

(b)

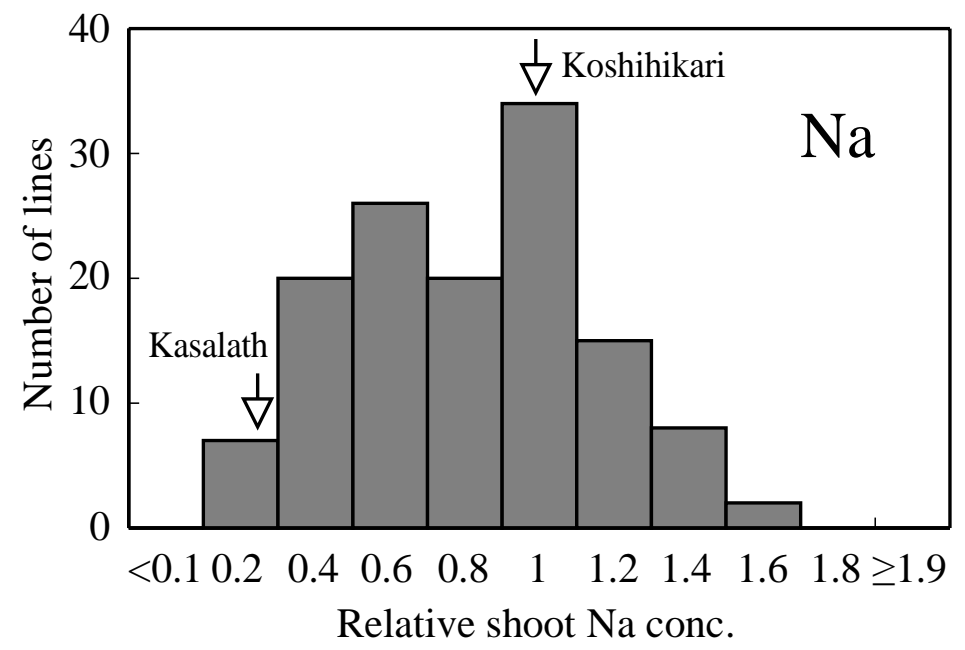

Figure 3 Frequency distributions of shoot $\mathrm{K}$ and $\mathrm{Na}$ concentrations of 10-day-old seedlings of BIL populations derived from Koshihikari and Kasalath. (a) Shoot K concentration, (b) shoot Na concentration. Arrows indicate $\mathrm{Na}$ and $\mathrm{K}$ concentrations of the parent cultivars. Plants were grown in a culture solution containing $0.08 \mathrm{~mol} \mathrm{~m}^{-3} \mathrm{KCl}$ and $0.38 \mathrm{~mol} \mathrm{~m}^{-3} \mathrm{NaCl}$. $\mathrm{K}$ and $\mathrm{Na}$ concentrations are shown as the ratio with respect to Koshihikari. Analysis of elements was performed for 10 bulked plants for each line or cultivar. 
Chr. 3

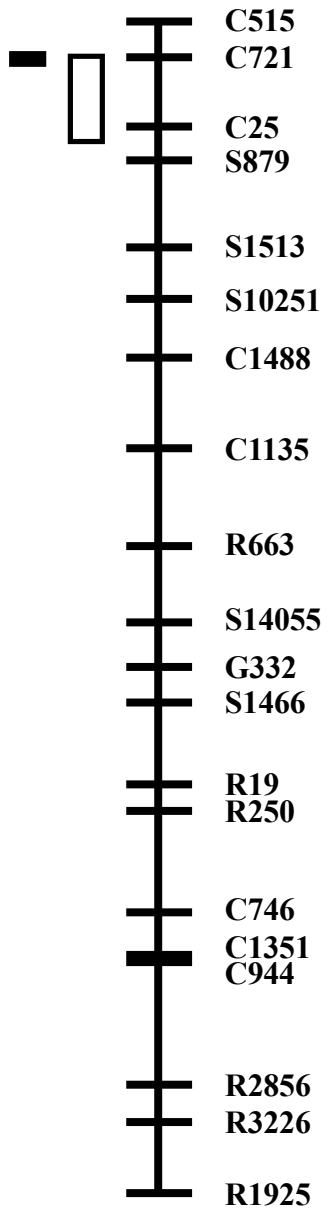

Chr. 6
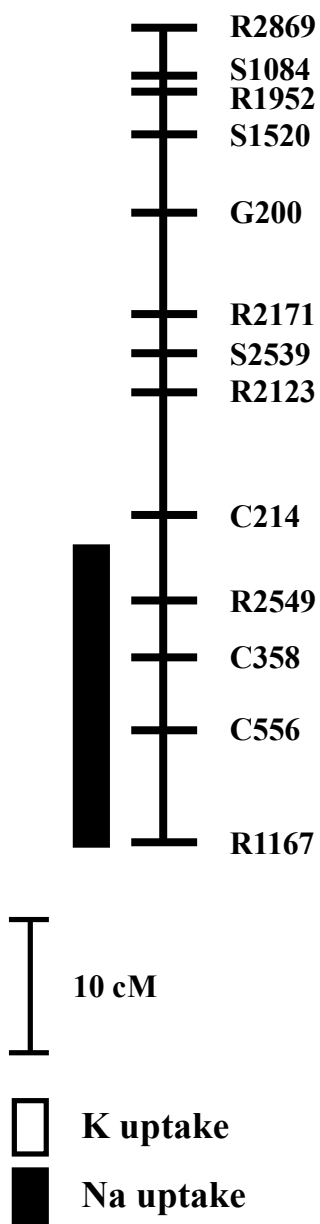

Figure 4 QTLs for shoot $\mathrm{K}$ and shoot Na concentrations in BILs derived from Koshihikari and Kasalath. Data for the linkage map were obtained from Rice Genome Resource Center (http://www.rgr.dna.affrc.go.jp/jp/index.html). Marker names are indicated on the right of each linkage map. Bars on the left of the linkage maps indicate chromosome regions in which LOD values exceeded the threshold determined by the 1000 permutation tests. 


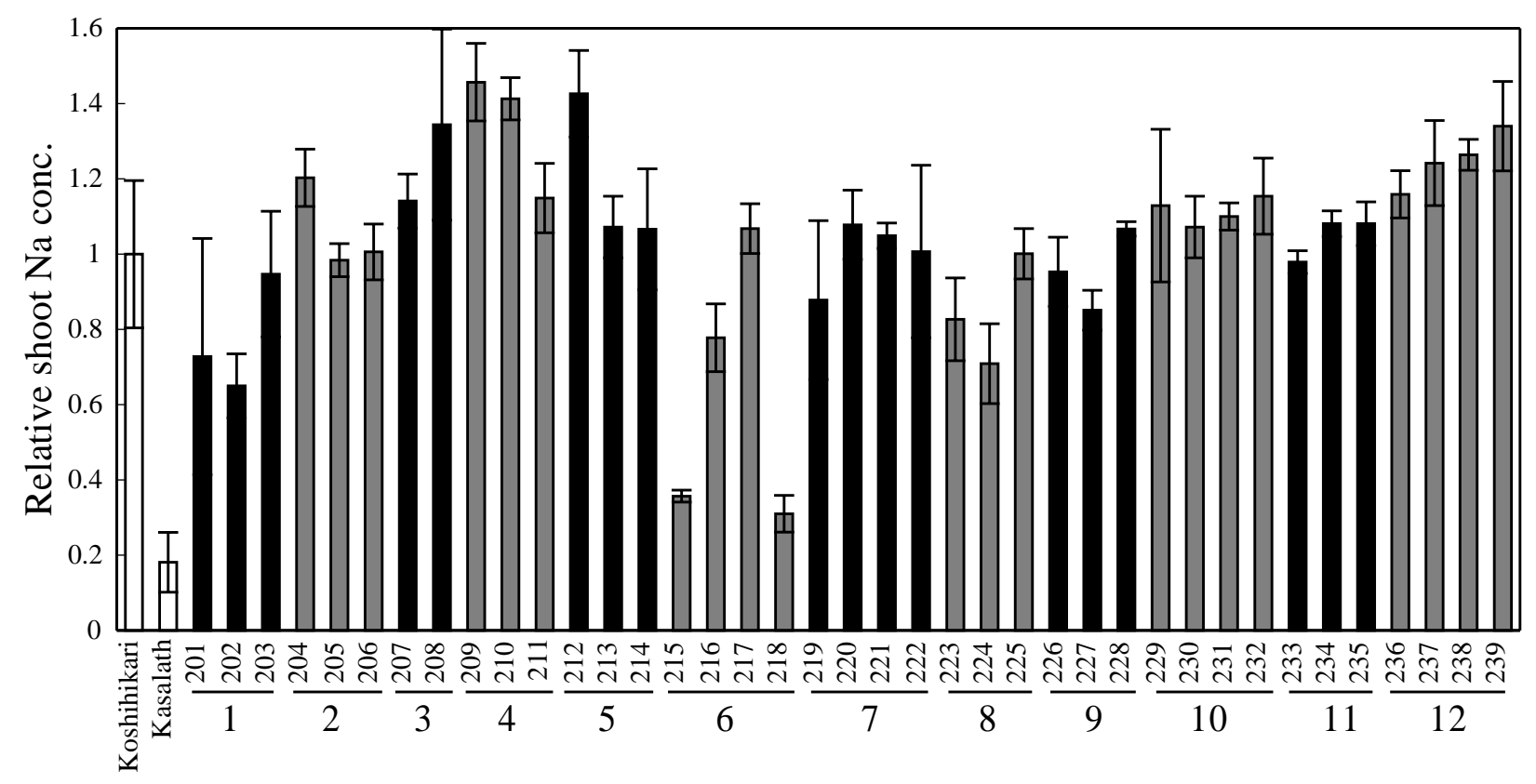

Figure 5 Relative shoot Na concentration of 9-day-old CSSLs (201-239) and their parent

cultivars. Plants were grown in culture solution containing $\mathrm{KCl}$ at $0.38 \mathrm{~mol} \mathrm{~m}^{-3}$ and $\mathrm{NaCl}$ at 0.38 mol $\mathrm{m}^{-3}$. Values are means with SD ( $\mathrm{n}=3$ for CSSLs and $\mathrm{n}=21$ for Koshihikari and Kasalath).

CSSLs carrying a segment from Kasalath on the same chromosome are distinguished by different colors. Numbers under line numbers indicate the chromosome in which the substitution occurred. 


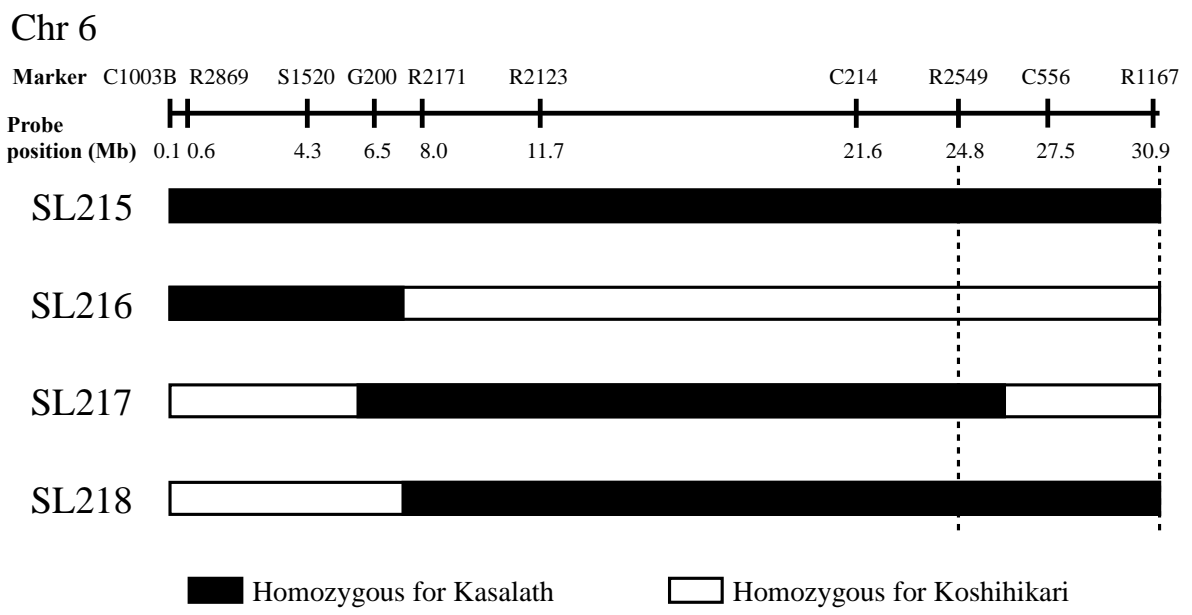

Figure 6 Graphical genotypes of SL215, SL216, SL217, and SL218. Genotype data were obtained from the Rice Genome Resource Center (http://www.rgr.dna.affrc.go.jp/jp/index.html). The physical position of the probes is based on the Os-Nipponbare-Reference-IRGSP-1.0. 